EPJ Web of Conferences 56, 02001 (2013)

DOI: $10.1051 /$ epjconf/20135602001

(C) Owned by the authors, published by EDP Sciences, 2013

\title{
Modelling desiccation shrinkage of large structures
}

\author{
F. Benboudjema ${ }^{1, a}$, and J.-M. Torrenti ${ }^{2}$ \\ ${ }^{1}$ LMT/ENS Cachan/CNRS UMR8535/UPMC/PRES UniverSud Paris, Cachan, France \\ ${ }^{2}$ Université Paris Est, IFFSTAR, 58, boulevard Lefebvre, 75732 Paris, France
}

\begin{abstract}
Drying of cement-based materials induces drying shrinkage, which may cause prestress loss or/and cracking if strains are (self or externally) restrained. Drying shrinkage is difficult to predict, since it depends on the material mix, mechanical and hygral boundary conditions, geometry ... This paper focuses on the study of size effect on final drying shrinkage, which is not well documented in the literature. In the Eurocode 2 (European code model), a reduction factor is applied for large structure, which is in agreement with experimental data of one campaign (found in the literature). Using numerical simulations, it is shown that a large panel of models, including phenomenological models as physical ones (which takes into account of (aging) creep under capillary pressure (assumed to be the physical mechanism for drying shrinkage)), do not predict size effect on final value of drying shrinkage.
\end{abstract}

\section{INTRODUCTION}

Drying of cement-based materials induces drying shrinkage, which may cause prestress loss or/and cracking if strains are (self or externally) restrained. Drying shrinkage is difficult to predict, since it depends on the material mix, mechanical and hygral boundary conditions, geometry ... Another difficulty is to take into account size effect on final drying shrinkage. A lot of experimental data and models are available concerning drying and induced drying shrinkage and cracking. However, some phenomena have still not been deeply investigated as the effect of size effect on final value of drying shrinkage. Indeed, it is obvious that the increase of the structure size slows the drying shrinkage kinetic (since drying is a diffusive process). On the contrary, it is not straightforward that the structure size may influence the final value of drying shrinkage. Besides, for large structure, drying may last more than one century! In the literature, only 2 papers have been found $[1,2]$, showing that there is a significant effect of structure size on final drying shrinkage (but with a significant difference between these 2 contributions, see Figure 1). In the European Code model (Eurocode 2, [3]), a reduction factor is applied to minor final drying shrinkage, which ranges from 1 to 0.7 , depending on the notional size of the structural member. It should be pointed out, that the ACI 209 Code model [4] or the new fib 2010 model do not introduce such a reduction factor. In order to predict drying shrinkage, it is thus important to dispose of a relevant predictive model (based on chemo-physical mechanisms).

The objective of this paper is to perform a thorough investigation on this subject. Since drying is not uniform in the specimens, finite elements calculations are needed to investigate deeply drying

\footnotetext{
a e-mail: farid.benboudjema@dgc.ens-cachan.fr
}

This is an Open Access article distributed under the terms of the Creative Commons Attribution License 2.0, which permits unrestricted use, distribution, and reproduction in any medium, provided the original work is properly cited. 
shrinkage. Using experimental results of a concrete representative of a French nuclear containment [5], numerical simulations are performed with a model developed by the authors, taking into account the main phenomena that occur in concrete during drying (water loss, shrinkage, creep, cracking) and the size effect on mechanical properties (tensile strength at this time). The comparison with others approaches as well as 2 classical drying shrinkage models are performed.

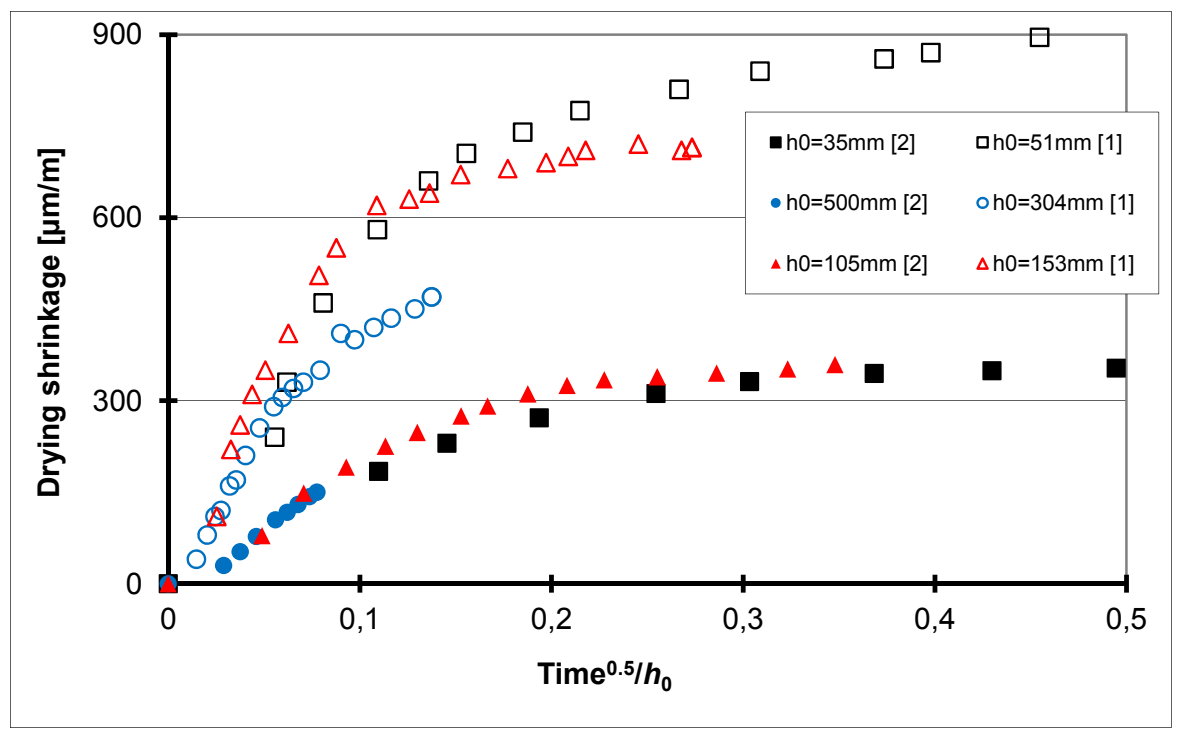

Fig. 1. Evolution of drying shrinkage (for different volume to surface ratio: $h_{0} / 2$ ) with respect to the square root of time to $h_{0}$ ratio [1,2]. Only partial data are displayed for sake of clarity.

\section{MODELING}

\subsection{Drying}

The drying of cement-based materials is a complex phenomenon. Several, more-or-less coupled, mechanisms are involved: permeation, diffusion, adsorption-desorption and condensationevaporation. Drying can be analyzed through the resolution of liquid water, vapor and dry air mass balance equations. The use of several hypotheses [6,7] allows for considering only the mass balance equation of liquid water:

$$
\frac{d S_{l}}{d p_{c}} \frac{d p_{c}}{d t}=\operatorname{div}\left(k_{r l}\left(S_{l}\right) \frac{K}{\mu_{l} \phi} \cdot \operatorname{grad}\left(p_{c}\right)\right)
$$

where $S_{l}, p_{c}, \phi, K, k_{r l}$ and $\mu_{l}$ are, respectively, the saturation degree, the capillary pressure, the porosity, the intrinsic permeability, the relative permeability and the viscosity of the liquid water. Mainguy et al. [6] and Thiery et al. [7] showed that this equation is sufficient for an accurate prediction of the drying of ordinary and high-performance concretes at $20^{\circ} \mathrm{C}$ with a relative humidity greater than $50 \%$. The capillary pressure and the relative permeability are related to the degree of saturation through van Genuchten's relation [8]:

$$
\left.p_{c}\left(S_{l}\right)=a\left(S_{l}^{-b}-1\right)^{1-1 / b} \text { and } k_{r l}\left(S_{l}\right)=\sqrt{S_{l}} \mid 1-\left(1-S_{l}^{b}\right)^{1 / b}\right\rfloor^{2}
$$

where $a$ and $b$ are parameters of the material. 


\subsection{Cracking}

The damage model proposed by Mazars [9] has been slightly modified [10]. In this model, a scalar mechanical damage variable is associated to the mechanical degradation process of concrete induced by the development of microcracks. The relationship, between apparent stress $\boldsymbol{\sigma}$, effective stress $\widetilde{\boldsymbol{\sigma}}$, damage $D$ (depending also on tensile strength $f_{t}$ ), elastic stiffness tensor $\mathbf{E}$, elastic strain $\boldsymbol{\varepsilon}_{e}$, creep strain $\boldsymbol{\varepsilon}_{c}$ (sum of basic and drying creep), drying shrinkage $\boldsymbol{\varepsilon}_{d s}$, and total strain $\boldsymbol{\varepsilon}$, reads:

$$
\sigma=(1-D) \widetilde{\sigma} \quad \text { and } \quad \dot{\widetilde{\sigma}}=E \dot{\varepsilon}_{e}=E\left(\dot{\varepsilon}-\dot{\varepsilon}_{c}-\dot{\varepsilon}_{d s}\right)
$$

\subsection{Basic creep}

The model used for creep strain evolution is based on the microprestress theory proposed by Bazant et al. [11] which has been enhanced in order to predict that basic creep depends on the internal relative humidity [12] (and that a completely dried concrete specimen does not creep at all [13]). This model turns out to be particularly accurate when considering a very long time creep (which is the case here), and is in good accordance with experimental results (cf. the experimental campaign by Brooks [14] for 30 years creep). The evolution of irreversible creep reads:

$$
\frac{d \varepsilon_{b c_{-} i}}{d t}=\widetilde{\sigma} \frac{\alpha}{t} S_{l}^{n}
$$

where $\alpha$ is a material parameter. The last right term, depending upon saturation degree, takes into account that the viscosity increases rapidly as drying occurs, leading to a decrease of basic creep strains as previously aforementioned.

In order to reproduce the (partial) reversible part of basic creep, a Kelvin-Voigt chain is used:

$$
\frac{\tilde{\sigma}}{k}=\varepsilon_{b c_{-} r}+\tau_{K V} \frac{d \varepsilon_{b c_{-} r}}{d t}
$$

Where $k$ is the stiffness of the spring, $\tau_{K V}$ is the characteristic time of the Kelvin-Voigt chain.

\subsection{Drying creep}

The most used model is probably the stress-induced shrinkage one, proposed by Bažant and Chern [15], which is based on experimental observations. It has been used in this study:

$$
\dot{\boldsymbol{\varepsilon}}_{d c}=\mu|\dot{h}| \boldsymbol{\sigma}
$$

where $\mu$ is a material parameter. Creep is extended to multiaxial state of stress by the use of a creep Poisson ratio, which has been taken equal to the elastic one.

\subsection{Drying shrinkage - models based on capillary pressure}

The capillary pore pressure $p_{c}$ is derived from the Kelvin law, which states that the gaseous phase (air and water vapor) are in equilibrium (Figure 2). It should be noted that the disjoining pressure 
and surface tension (which are also possible mechanisms for drying shrinkage) have similar mathematical expression than the capillary pressure one and the use of these mechanisms will not change drastically the following results.

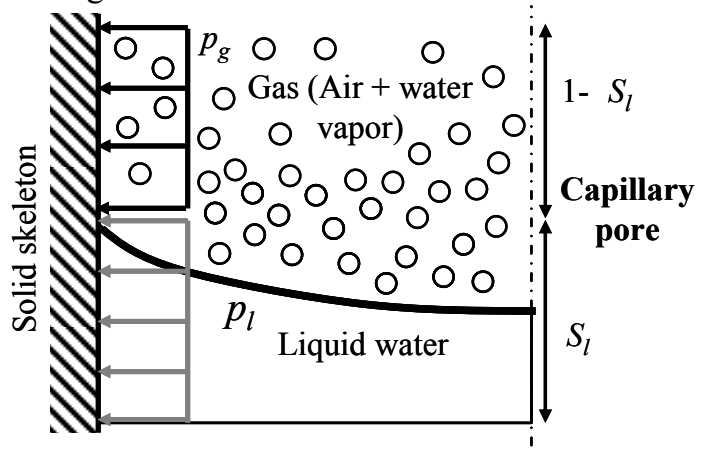

Fig. 2. The different pressures applied to the solid in the capillary pores.

Therefore, the pressure applied to the solid skeleton $p_{s}$ at the macroscopic scale is considered to result from a volume average of the capillary pressure:

$$
p_{s}=b S_{l} p_{c}
$$

where $b$ is the Biot coefficient which can be identified from a drying shrinkage test. The degree of saturation $S_{l}$ can be related to the relative humidity by means of the isotherm desorption curve (Eq. 2a).

Using the definition of effective stresses by Gawin et al. [16], the drying shrinkage results from the elastic and the creep response of the solid skeleton under the pore pressure (Eq. 7) (model C):

$$
\varepsilon_{d s}(t)=(1-2 v) b_{s c h}\left(\frac{S_{l} p_{c}}{E}+\int_{t^{\prime}=0}^{t^{\prime}=t} J\left(t-t^{\prime}, t^{\prime}\right) \frac{d\left(S_{l} p_{c}\right)}{d t^{\prime}} d t^{\prime}\right)
$$

where $v$ is the Poisson ratio and $J$ is the creep compliance. Using this formulation, it is possible to reproduce irreversible drying shrinkage (after rewetting) and effect of drying rate [17].

An alternative approach using the definition of stresses by Baroghel-Bouny et al. [18], the drying shrinkage reads (model D):

$$
\varepsilon_{d s}(t)=(1-2 v) b_{c o u}\left[\int_{t^{\prime}=0}^{t^{\prime}=t}\left(\frac{S_{l} d p_{c}}{E}+J\left(t-t^{\prime}, t^{\prime}\right) \frac{S_{l} d p_{c}}{d t^{\prime}}\right) d t^{\prime}\right]
$$

It is also supposed that the Biot coefficient is not dependent upon cracking. Such a dependency may explain part of drying creep [19], but this is out of the scope of this study.

\subsection{Drying shrinkage - phenomenological models}

Following experimental results, the (free) drying shrinkage rate $\dot{\boldsymbol{\varepsilon}}_{d s}$ may be taken as proportional to the water content variation $[5,20]($ model A):

$$
\dot{\boldsymbol{\varepsilon}}_{d s}=k_{d s} \dot{C} \mathbf{1}
$$

where $k_{d s}$ is a hydrous compressibility factor and $\mathbf{1}$ is the unit vector. 
An alternative approach is to take the drying shrinkage proportional to relative humidity [15] (model B):

$$
\dot{\boldsymbol{\varepsilon}}_{d s}=K_{d s} \dot{h} \mathbf{1}
$$

where $K_{d s}$ is a hydrous compressibility factor.

\section{FINITE ELEMENT SIMULATIONS}

As seen in the introduction, very few experimental results are available in the literature on the effect of size on drying shrinkage. Besides, in these two studies, evolution of drying has not been unfortunately studied (through weight loss measurements, for instance), which limits the efficiency of numerical simulations. Therefore, experimental results of Granger [5] are used. Indeed, most of material parameters, needed to predict drying shrinkage, have been measured, on cylindrical specimens: diameter of $16 \mathrm{~cm}$ and height of $1 \mathrm{~m}$, during almost 3 years. Only desorption isotherm characterization is lacking. Several concrete mixes have been studied. This study focus on an ordinary concrete with a $\mathrm{w} / \mathrm{c}=0.57$ ).

All the mechanical, drying, creep and drying shrinkage parameters are identified form experimental data of Granger [5], expect for the desorption isotherm (experimental results obtained by Philajavaara [21] on a similar concrete mix have been used). All identified parameters are given in Table 1.

Table 1. Material parameters.

\begin{tabular}{|c|c|c|c|c|c|c|c|}
\hline$a[\mathrm{MPa}]$ & $b$ & $K\left[\mathrm{~m}^{2}\right]$ & $E[\mathrm{GPa}]$ & $v$ & $f_{t}[\mathrm{MPa}]$ & $K_{d s}$ & $k_{d s}$ \\
\hline 58.2 & 2.43 & $1.15 \times 10^{-21}$ & 33.7 & 0.25 & 3.5 & $2 \times 10^{-3}$ & $10^{-5}$ \\
\hline$k[\mathrm{GPa}]$ & $\tau_{K V}[$ days $]$ & $\mu\left[\mathrm{Pa}^{-1}\right]$ & $\alpha\left[\mathrm{Pa}^{-1}\right]$ & $b_{s c h}$ & $\phi$ & $b_{c o u}$ & \\
\hline 113 & 10 & $3.2 \times 10^{-10}$ & $1.36 \times 10^{-11}$ & 0.65 & 0.13 & 0.55 & \\
\hline
\end{tabular}

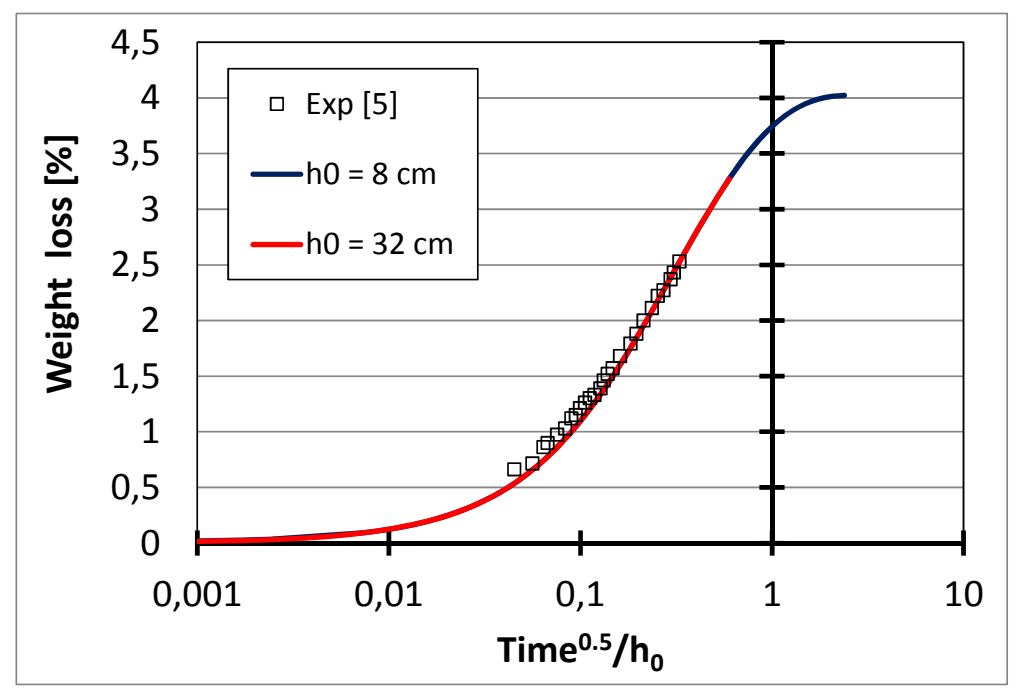

Fig. 3. Evolution of weight loss (for two different volume to surface ratio: $h_{0} / 2$ ) with respect to the square root of time to $h_{0}$ ratio.

Numerical simulations are performed on two cylindrical specimens: the first one has a diameter of $16 \mathrm{~cm}$ as the second one's diameter is $64 \mathrm{~cm}$ (both specimens have a height of $1 \mathrm{~m}$, and dry only 
by the lateral surface). Numerical simulations are performed during 100 years. At this time, only the predictive capacities of different drying shrinkage models have been tested.

Evolution of mass loss is plotted on Figure 3. It can be seen that experimental data are retrieved, and that it is corresponds to a diffusion type problem (i.e. controlled by the ratio between the square root of time and the radius).

\subsection{Phenomenological models}

The results are summarized in Figure 4, where drying shrinkage strains versus the square root of time to $h_{0}$ ratio are displayed. It shows that both models give very close results (if the material parameters are correctly identified) for the experience duration and diverge after about 75 years. Besides, a major part of the experimental curve is retrieved. However, the long term drying shrinkage (which was the topic of this paper) seem to be largely overestimated.

The comparison between the numerical results obtained for the two simulated sizes shows no significant size effect (on the amplitude of drying shrinkage). In contrary, results obtained with the model B (Equation 11) seems to show a very slight increase for drying shrinkage as the size increases.

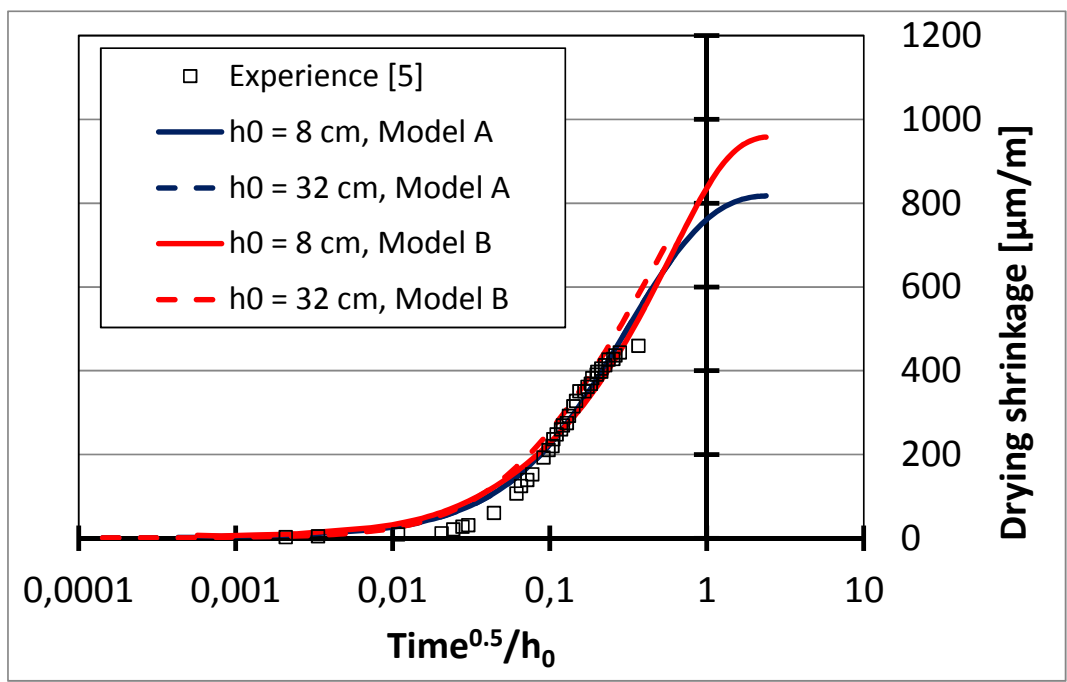

Fig. 4. Evolution of drying shrinkage, predicted by the two phenomenological models (for two volume to surface ratios: $h_{0} / 2$ ) with respect to the ratio between the square root of time and $h_{0}$. Models A and B corresponds to Equation 10 and 11, respectively.

\subsection{Models based on capillary pressure}

The results are summarized in Figure 5, where drying shrinkage strains versus the square root of time to $h_{0}$ ratio are displayed. It shows that both models give again very close results (if the material parameters are correctly identified) for the experience duration, and diverges after 1.5 years (early than what has been observed for the phenomenological models). Besides, a major part of the experimental curve is retrieved. However, again the long term drying shrinkage (which is the topic of this paper) seems to be largely overestimated for the model D, and slightly for the model C. Compared to experimental results of Granger [5] for a $8 \mathrm{~cm}$ radius specimen, Figure 4 and Figure 5 highlight that the model $\mathrm{C}$ seems to be the more appropriate model to retrieve experimental data. Somehow, it is important to note that it is necessary to use long term experimental data in order to discriminate models. Indeed, at the end of the tests performed by Granger [5] (2.4 years), no 
significant differences between all the models are found. At the end of numerical simulations (100 years), a maximal difference of about $33 \%$ is found (between $C$ and D models).

Besides, no significant size effect (on the amplitude of drying shrinkage) can be observed for the model D, where a very slight increase of drying shrinkage strains is observed. For the model C, a much more significant increase of drying shrinkage is even predicted which is in contradiction with the European code model [3] and experimental results of Hansen and Mattock [1]. However, it seems to be quite in agreement with l'Hermitte et al. [2] and Delaplace et al. [22] (the tests were performed for different sizes, but smaller sizes than the ones of the 2 aforementioned studies).

This obtained size effect may come from the effect of creep aging. Indeed, for a larger structure, drying reaches the inner parts later, and thus involves creep at later ages leading to lower drying shrinkage values (components due to basic creep only).

It should be noted that the decrease of the tensile strength of $30 \%$ (in order to take into account the size effect on the tensile strength [23]) does not modify significantly the results.

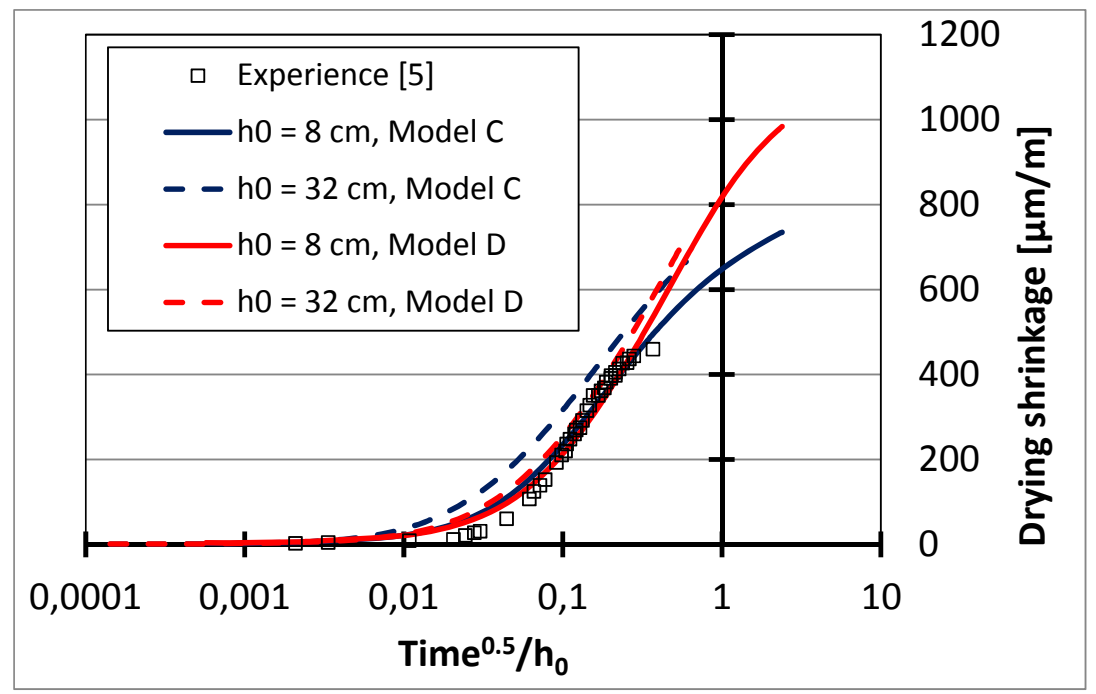

Fig. 5. Evolution of drying shrinkage, predicted by the two phenomenological models (for two volume to surface ratios: $h_{0} / 2$ ) with respect to the ratio between the square root of time and $h_{0}$. Models C and D corresponds to Equation 8 and 9, respectively.

\section{CONCLUSIONS}

The European code model [3] integrates a reduction factor for the final amplitude of drying shrinkage in large concrete structures. Such factor does not exist in ACI 209 code model [2]. Only two experimental results have been found by the authors in the available literature, they indicate such an effect but with different intensity. Four numerical (finite element) models (two phenomenological and two based on the capillary pressure) were used. They give very close results for the prediction of drying shrinkage during about 2 years: they allow for retrieving with a good agreement a major part of experimental drying shrinkage strains [5], but not the final behavior (which was the scope of this communication) for 3 of them. The model based on the definition of the effective stresses proposed by Gawin et al. [16] gives the best results. However, no significant size effects (a slight increase of drying shrinkage strains is even retrieved) are reproduced, which is quite in agreement with l'Hermitte et al. [2] and Delaplace et al. [22], and in contradiction with Hansen and Mattock [1]. A slight increase of drying shrinkage strains is even predicted for some of the models. Therefore, the problem of size effect on final drying shrinkage is still an open issue! 


\section{ACKNOWLEDGEMENTS}

The authors would like to thank the French national program CEOS.fr (http://www.ceosfr.org/) for its financial support.

\section{REFERENCES}

1. T.C. Hansen, A.H. Mattock, ACI J. 63, 267-290 (1966)

2. R.G. L'Hermite, M. Mamillan, C. Lefevre, Ann. Inst. Techn. Bâtiment Trav. Publics 18, 323 $360(1965)$

3. Eurocode 2: Design of concrete structures - Part 1-1: General rules and rules for buildings (EN 1992-1-1)

4. ACI Committee 209R-92, Prediction of Creep, Shrinkage, and Temperature Effects in Concrete Structures (American Concrete Institute, Farmington Hills, Mich, 1992

5. L. Granger, Comportement différé du béton dans les enceintes de centrales nucléaires: analyse et modélisation $(\mathrm{PhD}$ thesis, Ecole Nationale des Ponts et Chaussées, Marne-La-Vallée, France, 1996) (in french)

6. M. Mainguy, O. Coussy, V. Baroghel-Bouny, Journal of Engineering Mechanics 127, 582-592 (2001)

7. M. Thiery, V. Baroghel-Bouny, N. Bourneton, G. Villain, C. Stefani, Revue Européenne de Génie Civil 11, 541-577 (2007) (in french)

8. M Th. van Genuchten, Soil Science Society of America 44, 892-898 (1980)

9. J. Mazars, Engineering Fracture Mechanics 25, 729-737 (1986)

10. F. Benboudjema, Torrenti J.M., Nuclear Engineering and Design 238, 2495-2506 (2008)

11. Z.P. Bažant, A.B. Hauggaaed, S. Baweja, F.J. Ulm, Journal of Engineering Mechanics 123, 1188-1194 (1997)

12. Z.P. Bažant, A. Asghari, J. Scamiot, Materials and Structures 9, 279-290 (1976)

13. P. Acker, F.-J. Ulm, Nuclear Engineering Design 203, 143-158 (2001)

14. J. J. Brooks, Magazine of concrete research 57, 545-556 (2005)

15. Z. P. Bažant, J. C. Chern, Materials and Structures 18, 1-20 (1985)

16. D. Gawin, F. Pesavento, B. Schrefler, Materials and Structures 40, 579-591 (2007)

17. F. Benboudjema, F. Meftah, J.-M. Torrenti, Materials and Structures 40, 163-253 (2007)

18. V. Baroghel-Bouny, M. Mainguy, T. Lassabatere, O. Coussy, Cement and Concrete Research, 29,1225-1238 1999

19. A. Sellier, L. Buffo-Lacarrière, S. Multon, T. Vidal, X. Bourbon, Numerical Modeling Strategies for sustainable Concrete Structures (2012)

20. R.W. Carlson, J. of the Am. Concrete Inst. 33, 327-336 (1937)

21. S.E. Philajavaara, Cement and Concrete Research 4, 761-771 (1974)

22. Delaplace A., Noyalet H., $8^{\text {th }}$ International Conference on Fracture Mechanics of Concrete and concrete Structures (2013)

23. M.R.A. van Vliet, J. G.M. van Mier, Engineering Fracture Mechanics 65, 165-188 (2000) 